\title{
Associação entre genótipos de feijoeiro, silício e nim no controle da mosca-branca Bemisia tabaci (Gennadius, 1889) biótipo B (Hemiptera: Aleyrodidae) ${ }^{1}$
}

\author{
Marília Lara Peixoto ${ }^{*}$, Arlindo Leal Boiça Junior ${ }^{2}$ \\ 10.1590/0034-737X201764040006
}

\begin{abstract}
RESUMO
A mosca-branca Bemisia tabaci biótipo B causa grandes prejuízos ao feijoeiro, principalmente pela transmissão do vírus do mosaico dourado. O objetivo deste trabalho foi avaliar o efeito da associação de genótipos de feijão comum, com doses de óleo de nim e silício, no desenvolvimento e oviposição da mosca-branca. Os experimentos foram conduzidos em casa de vegetação, do Departamento de Fitossanidade da FCAV/UNESP, realizando-se dois experimentos para oviposição, ambos com e sem chance de escolha, e o teste de antibiose. De acordo com os dados obtidos, pode-se concluir que no primeiro experimento de oviposição, o silício $1 \%$ reduziu a oviposição da mosca-branca, em teste com chance de escolha, e o nim $1 \%$ reduziu a oviposição em ambos os testes. O óleo de nim proporcionou alta mortalidade de ninfas. No segundo experimento de oviposição, o menor número de ovos foi na dose de nim $0,75 \%$, para o teste com chance de escolha, e a dose de nim $1 \%$ foi melhor para o teste sem chance.
\end{abstract}

Palavras-chave: indução de resistência; Phaseolus vulgaris; produto natural.

\section{ABSTRACT}

\section{Association between bean genotypes, silicon, and neem in the control of whitefly Bemisia tabaci (Gennadius, 1889) biotype B (Hemiptera: Aleyrodidae)}

In bean plants, Bemisia tabaci biotype B causes great losses, especially through the transmission of golden mosaic virus. The aim of this work was to evaluate the effect of the association of common bean genotypes with doses of neem oil and silicon on the development and oviposition of whitefly. Experiments were carried out in a greenhouse, in the Plant Protection Department of FCAV/UNESP, where two oviposition tests were performed, free and no-choice, in addition to the antibiosis test. According to the data obtained, we concluded, in the first oviposition experiment, that silicon at $1 \%$ reduced the oviposition in free-choice test and neem at $1 \%$ reduced oviposition in both tests. Neem oil provided high mortality of nymphs. In the second oviposition experiment, the lowest number of eggs was found for the dose of neem at $0.75 \%$ in free-choice test and for neem at $1 \%$ in no-choice test.

Key words: induction of resistance; Phaseolus vulgaris; natural product.

\footnotetext{
Submetido em 22/02/2016 e aprovado em 05/07/2017.

'Este trabalho é parte da tese de doutorado da primeira autora.

¿Departamento de Fitossanidade, Faculdade de Ciências Agrárias e Veterinárias, Universidade Estadual Paulista "Júlio de Mesquita Filho”, Jaboticabal, São Paulo, Brasil . aboicajr@fcav.unesp.br; marilara19@yahoo.com.br
}

*Autora para correspondência: marilara19@yahoo.com.br 


\section{INTRODUÇÃO}

Phaseolus vulgaris L. é a espécie mais cultivada de feijoeiro comum dentro da família Fabaceae. A proteína do feijão é responsável por mais de $80 \%$ do total de proteínas da dieta da população brasileira, além de ser importante fonte de ferro (Aragão \& Faria, 2005).

A mosca-branca Bemisia tabaci (Gennadius, 1889) biótipo B (Hemiptera: Aleyrodidae) é uma das principais pragas do feijoeiro, pela sucção de seiva do floema, que altera o desenvolvimento vegetativo e reprodutivo das plantas e, principalmente, pela transmissão do vírus do mosaico dourado do feijoeiro, o Bean Golden Mosaic Virus (BGMV), com perdas que podem variar de 30 a $100 \%$. Esse percentual é influenciado pelo cultivar, pelo estádio de desenvolvimento da planta, por fatores como a densidade populacional da praga, pela presença de plantas hospedeiras alternativas na área de cultivo, ou próximas dela, e pelas condições ambientais (Faria et al., 1996).

$\mathrm{O}$ uso intenso de inseticidas gera grandes desequilíbrios ecológicos. Por isso, a demanda pela produção orgânica vem aumentando e pesquisas, empregando produtos naturais, como os extratos botânicos, vêm sendo realizadas (Carneiro, 2002; Martinez, 2002).

O nim, Azadirachta indica A. Juss., destaca-se entre as plantas com potencial inseticida e seus componentes ativos atuam em $B$. tabaci, causando repelência, deterrência na alimentação e na oviposição, redução da viabilidade de ovos e alterações no desenvolvimento de ninfas e adultos (Souza \& Vendramim, 2000; Silva et al., 2003; Azevedo et al., 2005).

Além do uso de inseticidas naturais, outras táticas de manejo devem ser utilizadas com o intuito de aprimorar o Manejo Integrado de Pragas, como, por exemplo, as práticas culturais que aumentem o grau de resistência das plantas, como o uso do silício (Goussain et al., 2002). Esse mineral pode conferir resistência às plantas por sua ação como elicitor do processo de resistência induzida, por meio de barreiras físicas ou químicas, estimulando o crescimento e a produção vegetal por meio de várias ações indiretas, como mudanças anatômicas nos tecidos, como células epidérmicas com a parede celular mais espessa, favorecendo a melhor arquitetura das plantas, deixando as folhas mais eretas e aumentando a capacidade fotossintética, propiciando proteção contra fatores abióticos, como estresses hídricos, toxidez de alumínio e ferro, entre outros, e fatores bióticos, como a incidência de insetos-pragas e doenças (Epstein, 1994; Gomes et al., 2008, 2009; Ferrari Neto, 2016). A silicificação da epiderme dificulta a penetração de estiletes e a mastigação pelos insetos, graças ao endurecimento da parede das células vegetais (Datnoff et al., 1991). Para B. tabaci, a aplicação de silício foliar aumentou o tempo até a primeira picada de prova e reduziu o tempo de alimentação, no floema, em genótipos de soja (Godoy, 2017).

Assim, objetivou-se, com este trabalho, avaliar o efeito da associação de genótipos de feijoeiro comum com óleo de nim e silício, na oviposição e desenvolvimento de B. tabaci biótipo B.

\section{MATERIAL E MÉTODOS}

Os experimentos foram conduzidos no Laboratório de Resistência de Plantas a Insetos e em casa de vegetação, onde as plantas foram mantidas em temperatura ambiente, do Departamento de Fitossanidade da Faculdade de Ciências Agrárias e Veterinárias da Universidade Estadual Paulista Júlio de Mesquita Filho, FCAV/UNESP, Jaboticabal, SP, em 2011 e 2012. Avaliaram-se os genótipos de feijoeiro resistente IAC-Harmonia, o genótipo susceptível Pérola, e um, intermediário, IACCarioca Tybatã, selecionados de testes realizados anteriormente para a mosca-branca B. tabaci biótipo B (Peixoto \& Boiça Júnior, 2014). As sementes de feijão foram semeadas a partir de maio de 2011, em vasos de polietileno com capacidade de cinco litros, sendo quatro sementes por vaso. As plantas foram desbastadas dez dias após a emergência, deixando-se uma planta por vaso. Os indivíduos de B. tabaci utilizados nos experimentos foram adquiridos da criação de manutenção, em casa de vegetação do setor de Entomologia da FCAV/UNESP, que eram mantidas em plantas de couve cultivar Manteiga Georgia (Brassica oleracea L. var. acephala). A referida criação iniciou-se a partir de moscas-brancas adquiridas do Setor de Entomologia do IAC (Instituto Agronômico de Campinas), identificadas como Bemisia tabaci biótipo B.

Foram realizados dois experimentos: um de não preferência para oviposição e outro de antibiose. No experimento de não preferência, foram testadas doses de óleo de nim, pulverizadas até o ponto de escorrimento nas plantas e, o silício, aplicado por via do solo e por via foliar. Para a antibiose, o silício foi aplicado por via do solo e as ninfas da mosca-branca foram imersas na emulsão de óleo de nim. O produto comercial de óleo de nim utilizado foi o AZAMAX®, um concentrado emulsionável à base de azadiractina, do grupo dos tetranortriterpenoides, com $1,2 \%$ de azadiractina ( $12 \mathrm{~g} / \mathrm{L})$. Esse produto foi introduzido no mercado brasileiro em 2009, sendo o único registrado no Ministério da Agricultura, Pecuária e Abastecimento (MAPA), para o controle de pragas na agricultura, e certificado pelo Instituto Biodinâmico (IBD), para emprego em sistemas de produção orgânica. Com relação à fonte de silício, foi utilizado o silicato de sódio $\left(\mathrm{Na}_{2} \mathrm{SiO}_{3}\right)$, na concentração de 20 a $30 \%$ de $\mathrm{SiO}_{2}$. 
O delineamento experimental foi de blocos casualizados, para o teste com chance de escolha e inteiramente casualizado, para os testes sem chance de escolha e de antibiose.

\section{Teste de não preferência para oviposição de B. tabaci biótipo $B$}

Os tratamentos avaliados nesse experimento foram: T1 - Silício solo 1\%; T2 - Silício solo 0,50\%; T3 - Silício foliar 0,25\%; T4 - Silício foliar 0,125\%; T5 - Nim 0,75\%; T6 - Nim 1\%; T7 - Testemunha. Os testes foram realizados 20 dias após a emergência das plantas. Foram realizadas três aplicações de silício no solo, correspondendo à dose de 2 t/ha, sendo $500 \mathrm{~mL}$ de solução para cada vaso, com intervalo de cinco dias entre as aplicações, sendo a primeira aplicação realizada cinco dias após a emergência das plantas. A única aplicação do silício foliar foi feita com pulverizador manual até o ponto de escorrimento, cinco dias antes da montagem do experimento. O nim foi aplicado uma única vez, com pulverizador manual comum, com bico spray, até o ponto de escorrimento, e esperouse cerca de 30 minutos para a liberação dos insetos. $\mathrm{O}$ delineamento seguiu esquema fatorial $3 \times 7$, representando os genótipos de feijão e os tratamentos, respectivamente, totalizando 21 tratamentos e seis repetições.

No teste com chance de escolha, utilizou-se gaiola de metal (1,5 m de comprimento $x$ 1,5 $\mathrm{m}$ de largura $\mathrm{x} 1,8 \mathrm{~m}$ de altura), revestida por tela antiafídeo, sendo que cada gaiola corresponde a um bloco. Em cada gaiola, foi colocada uma planta de cada tratamento, totalizando 21 plantas por gaiola. Foram liberados, ao centro e equidistantes das plantas, 100 adultos de mosca-branca por tratamento, totalizando 2.100 indivíduos por gaiola. No teste sem chance de escolha, foi realizada a individualização de cada tratamento em gaiolas cilíndricas de metal $(60 \mathrm{~cm}$ de altura x $40 \mathrm{~cm}$ de diâmetro), revestida por tecido voile, e os tubos de ensaio, com 100 adultos não sexados da moscabranca por tubo, foram colocados na base da planta, sendo um tubo por planta totalizando 12.600 adultos para o teste. Para ambos os testes, os adultos foram retirados 48 horas após a infestação, com a remoção das plantas para o exterior da estufa, e movimentando-se as folhas até que todos os adultos fossem eliminados. Fez-se a contagem de ovos na face abaxial de todas as folhas das plantas com estereomicroscópio, em laboratório, e foi medida a área foliar com o aparelho LI-COR modelo $3100 \AA$, para obtenção do número médio de ovos por $\mathrm{cm}^{2}$.

Teste de antibiose em B. tabaci biótipo $\mathrm{B}$, em genótipos de feijão comum

Os tratamentos para o teste de antibiose foram: T1 - Silício solo 1\%; T2 - Nim 1\%; T3 - Silício solo 1\% + nim 0,25\%; T4 - Nim 0,75\%; T5 - Nim 0,50\%; T6 - Nim 0,25\%; T7 Testemunha. $\mathrm{O}$ delineamento ficou disposto em esquema fatorial $3 \times 7$, representando os genótipos de feijão e os tratamentos, respectivamente, totalizando 21 tratamentos e cinco repetições. Cada planta correspondeu a uma repetição e as plantas foram utilizadas com 20 dias após a emergência. Para obtenção de ovos, foram coletados 60 adultos de $B$. tabaci biótipo B da criação de manutenção, com um sugador de borracha acoplado a um tubo de ensaio de vidro, os quais foram liberados em pequenas gaiolas, confeccionadas conforme a metodologia de Campos et al. (2009). Essas gaiolas foram feitas com copos plásticos com capacidade para 40 $\mathrm{mL}$, cujo fundo foi retirado, sendo a extremidade maior protegida por tecido voile e a extremidade menor por tampa, feita com espuma e papelão, e fixada na lateral do copo por um grampo. Para a fixação da gaiola ao solo foi acoplada uma haste de madeira, colocando-se uma gaiola por planta. Decorridas 24 horas, as gaiolas com os adultos foram retiradas e as folhas contendo os ovos foram marcadas. Após a eclosão e fixação das ninfas, foram separadas inicialmente 30 ninfas e, cinco dias após sua eclosão, foram escolhidas 20 ninfas por repetição. As folhas contendo as ninfas foram imersas nas emulsões dos respectivos tratamentos de doses de óleo de nim, por dez segundos. O desenvolvimento das ninfas foi acompanhado diariamente com lupa, observando-se sua sobrevivência. Determinaram-se os parâmetros biológicos: duração do período ninfal, mortalidade de ninfas com um, três e seis dias após a aplicação do óleo de nim, mortalidade de ninfas total e período médio de mortalidade de ninfas. Por ocasião do quarto ínstar ninfal, ou seja, na fase de "pupa", foram colocados saquinhos de voile nas folhas, em que foram coletados, com sugador manual, os adultos emergidos, a seguir individualizados em tubos de ensaio, armazenados em laboratório, a $26 \pm 2{ }^{\circ} \mathrm{C}$, e umidade relativa de $70 \pm 5 \%$ e fotofase de 12 horas, sem alimentação, para a avaliação da longevidade.

Para análise estatística, os dados foram submetidos à análise de variância pelo teste $\mathrm{F}$, sendo as médias comparadas pelo teste de Tukey, a 5\% de probabilidade. Os dados de contagem foram transformados em $\log (x+5)$ e a mortalidade em arcoseno $(\mathrm{x} / 100)^{1 / 2}$, com o programa estatístico AgroEstat (Barbosa \& Maldonado Junior, 2010).

\section{RESULTADOS E DISCUSSÃO}

\section{Teste de não preferência para oviposição de B. tabaci biótipo $B$}

Quanto ao número de ovos de B. tabaci biótipo B, não houve diferenças significativas entre os genótipos de feijoeiro, para os testes com e sem chance de escolha (Tabela 1). Em relação aos tratamentos, pode-se afirmar que o óleo de nim na dose de $0,75 \%$ foi eficaz para a redução do número de ovos de B. tabaci biótipo B, assim como o óleo de nim a $1 \%$, o silício foliar a $0,125 \%$, ou o silício, por via do solo, na dose $1 \%$. 
Rheinheimer et al. (2012) observaram que o óleo de nim reduziu a oviposição de Bemisia tuberculata (Bondar, 1923), com eficiência de 70\%, em plantas de mandioca, e relataram que essa diminuição do número de ovos pode ter sido causada pela mortalidade das fêmeas, antes de ovipositarem, ou pela repelência aos adultos por compostos voláteis presentes nesse produto, fato provavelmente ocorrido nesta pesquisa. Quintela \& Pinheiro (2009) obtiveram redução da oviposição de B. tabaci biótipo B acima de $80 \%$, quando pulverizado óleo de nim na face inferior de folhas de feijoeiro, em concentrações maiores que $1 \%$, e diminuição do número de ovos, com o aumento da concentração dos produtos testados. Almeida et al. (2008), testando diferentes formas e quantidade de aplicações de silício, observaram que duas aplicações do fertilizante organomineral (por via do solo e por foliar) e três aplicações (por via do solo e duas por via foliar) reduziram significativamente o número de ovos de $\mathrm{B}$. tabaci biótipo B em feijão comum. Correa et al. (2005) verificaram que duas aplicações de silicato de cálcio por via foliar proporcionaram redução do número de ovos da moscabranca, em relação a uma aplicação por via do solo, em plantas de pepino. Os resultados obtidos nesses estudos levam a concluir que o silício deve ser aplicado mais de uma vez, tanto por via do solo, quanto por via foliar.

\section{Teste de antibiose de B. tabaci biótipo B, em genótipos de feijão comum}

Não foi observada diferença significativa para a mortalidade de ninfas entre os genótipos avaliados, para o primeiro, terceiro e sexto dias após a aplicação do óleo de nim. Para os tratamentos, observou-se maior mortalidade na dose de $0,75 \%$, para o primeiro e terceiro dia após a aplicação do óleo de nim. Para o sexto dia, as doses de 0,75 e $1 \%$ de óleo de nim, e silício $1 \%$ + nim $0,25 \%$ não diferiram estatisticamente entre si (Tabela 2). De modo geral, esses resultados indicam que o óleo de nim, associado a genótipos de feijoeiro comum, apresenta potencial para utilização no controle de $B$. tabaci biótipo $\mathrm{B}$, sendo a dose de $0,75 \%$ a mais eficiente para as três avaliações (primeiro, terceiro e sexto dias). Em relação à mortalidade de ninfas total, os genótipos avaliados não diferiram significativamente entre si. Entre os tratamentos, o óleo de nim, nas doses de 0,75 e $1 \%$, proporcionaram $100 \%$ de mortalidade, sem diferir significativamente das doses de óleo de nim de $0,25 \%$, nim $0,50 \%$ e silício $1 \%+\operatorname{nim} 0,25 \%$. Bleicher et al. (2007) obtiveram redução da média de ninfas vivas na menor dose (12 ppm) de azadiractina (produto comercial) com eficiência de $82,3 \%$. Para o extrato aquoso de sementes a $1 \%$, foi obtida eficiência de $71,1 \%$ e para a concentração de $16 \%$, a eficiência foi de $97,00 \%$, quando pulverizados sobre ninfas de primeiro ínstar de B. tabaci biótipo B, na cultura do melão. Souza \& Vendramim (2000) obtiveram $89,79 \%$ de eficiência de extrato aquoso de semente de nim, na concentração de $3 \%$, para a mortalidade de ninfas de mosca-branca na cultura do tomate. A utilização de compostos com diferentes modos de ação, como o nim e outros extratos botânicos, é importante para o manejo da mosca-branca, já que nenhum estádio de desenvolvi-

Tabela 1: Número médio de ovos de Bemisia tabaci biótipo B por $\mathrm{cm}^{2}$ de folíolo, em genótipos de feijoeiro, associado com óleo de nim e silício, em testes com e sem chance de escolha, em casa de vegetação. Jaboticabal, SP, 2012

\begin{tabular}{|c|c|c|}
\hline \multirow{2}{*}{ Genótipos (G) } & \multicolumn{2}{|c|}{ Número de ovos/ $/ \mathrm{cm}^{2}$} \\
\hline & Teste com chance ${ }^{(1)}$ & Teste sem chance $^{(1)}$ \\
\hline IAC-Harmonia & $0,25 \mathrm{a}$ & $0,48 \mathrm{a}$ \\
\hline IAC-Carioca Tybatã & $0,29 \mathrm{a}$ & $0,50 \mathrm{a}$ \\
\hline Pérola & $0,17 \mathrm{a}$ & $0,68 \mathrm{a}$ \\
\hline $\mathrm{F}(\mathrm{G})$ & $1,89^{\mathrm{NS}}$ & $2,19^{\mathrm{NS}}$ \\
\hline \multicolumn{3}{|l|}{ Tratamentos $(\mathrm{T})$} \\
\hline Silício solo $1 \%$ & $0,17 \mathrm{~b}$ & $0,43 \mathrm{bc}$ \\
\hline Silício solo $0,50 \%$ & $0,32 \mathrm{ab}$ & $0,71 \mathrm{ab}$ \\
\hline Silício foliar $0,25 \%$ & $0,24 \mathrm{ab}$ & $0,44 \mathrm{bc}$ \\
\hline Silício foliar $0,125 \%$ & $0,18 \mathrm{~b}$ & $0,50 \mathrm{bc}$ \\
\hline $\operatorname{Nim} 0,75 \%$ & $0,07 \mathrm{~b}$ & $0,39 \mathrm{bc}$ \\
\hline Nim $1 \%$ & $0,19 \mathrm{~b}$ & $0,28 \mathrm{c}$ \\
\hline Testemunha & $0,49 \mathrm{a}$ & $1,11 \mathrm{a}$ \\
\hline $\mathrm{F}(\mathrm{T})$ & $4,32 * *$ & $6,83 * *$ \\
\hline $\mathrm{F}(\mathrm{G} \times \mathrm{T})$ & $0,54^{\mathrm{NS}}$ & $1,12^{\mathrm{NS}}$ \\
\hline C.V. $(\%)$ & 3,02 & 4,40 \\
\hline
\end{tabular}

${ }^{(1)}$ Médias seguidas de mesma letra na coluna não diferem estatisticamente entre si pelo teste de Tukey, a 5\% de probabilidade. Para análise, os dados foram transformados em $\log (\mathrm{x}+5)$. Na tabela, os dados são originais. Ns Não significativo. **Significativo. 
mento apresenta resistência ao nim indiano (Prabhaker et al., 1989). Em relação à aplicação de silício $1 \%$ no solo, e à associação entre os dois produtos, apesar de não ter sido observada uma mortalidade eficiente para o primeiro, terceiro e sexto dias de avaliação, a mortalidade total obtida foi elevada.

Os resultados apresentados neste trabalho corroboram os obtidos por Peixoto et al. (2011), que, avaliando o número médio de ninfas de B. tabaci biótipo B, obtiveram redução de mais da metade de ninfas quando houve aplicação de ácido silícico a 1\%, no solo, em plantas de feijão comum. Entretanto, Vieira et al. (2012), avaliando a ação de produtos comerciais à base de nim e silício e a eficiência dos dois produtos utilizados conjuntamente para repelência de adultos, número de ovos e de ninfas de Bemisia tabaci biótipo B, não verificaram diferença significativa entre os tratamentos, em plantas de soja.

Para a interação entre os genótipos de feijoeiro versus aplicações dos produtos, observou-se diferença significativa para o terceiro dia de avaliação. Verificou-se diferença significativa para as doses de óleo de nim 0,75 e 1\%, entre os diferentes genótipos (Tabela 3). Esses resultados mostram a eficiência do óleo de nim na mortalidade das ninfas da mosca-branca, de mais de $50 \%$, para todos os genótipos avaliados, ao terceiro dia após a aplicação

Tabela 2: Mortalidade média, aos $1^{\circ}, 3^{\circ}$ e $6^{\circ}$ dias após aplicação das doses de óleo de nim e silício e total de ninfas (\%) de Bemisia tabaci biótipo B, obtidas em genótipos de feijoeiro em casa de vegetação. Jaboticabal, SP, 2012

\begin{tabular}{|c|c|c|c|c|}
\hline \multirow{2}{*}{ Genótipos (G) } & \multicolumn{3}{|c|}{ Mortalidade $^{(1)}$} & \multirow{2}{*}{ Mortalidade total $^{(1)}$} \\
\hline & $1 \mathrm{DAP}(2)$ & $3 \mathbf{D A P}^{(2)}$ & $6 \mathrm{DAP}^{(2)}$ & \\
\hline IAC-Harmonia & $40,86 \mathrm{a}$ & $62,21 \mathrm{a}$ & $76,32 \mathrm{a}$ & $87,28 \mathrm{a}$ \\
\hline IAC-Carioca Tybatã & $46,00 \mathrm{a}$ & $63,83 \mathrm{a}$ & $77,14 \mathrm{a}$ & 86,00 a \\
\hline Pérola & $42,14 \mathrm{a}$ & $63,00 \mathrm{a}$ & $75,14 \mathrm{a}$ & 86,86 a \\
\hline$F(G)$ & $0,93^{\mathrm{NS}}$ & $0,24^{\mathrm{NS}}$ & $0,45^{\mathrm{NS}}$ & $2,09^{\mathrm{NS}}$ \\
\hline \multicolumn{5}{|l|}{ Tratamentos $(\mathrm{T})$} \\
\hline Silício 1\% & $21,33 \mathrm{~d}$ & $42,33 \mathrm{~d}$ & $64,00 \mathrm{c}$ & $95,00 \mathrm{~b}$ \\
\hline $\operatorname{Nim} 1 \%$ & $67,33 \mathrm{ab}$ & $86,67 \mathrm{ab}$ & 96,33 a & $100,00 \mathrm{a}$ \\
\hline Silício $1 \%+\operatorname{Nim} 0,25 \%$ & $51,00 \mathrm{bc}$ & $78,67 \mathrm{bc}$ & $91,33 a b$ & $99,67 \mathrm{a}$ \\
\hline $\operatorname{Nim} 0,75 \%$ & $75,00 \mathrm{a}$ & $92,11 \mathrm{a}$ & $98,75 \mathrm{a}$ & $100,00 \mathrm{a}$ \\
\hline $\operatorname{Nim} 0,50 \%$ & $52,00 \mathrm{bc}$ & $75,67 \mathrm{bc}$ & $88,33 \mathrm{~b}$ & $98,33 \mathrm{ab}$ \\
\hline $\operatorname{Nim} 0,25 \%$ & $34,33 \mathrm{~cd}$ & $63,33 \mathrm{~cd}$ & $83,33 \mathrm{bc}$ & $99,33 \mathrm{a}$ \\
\hline Testemunha & $0,00 \mathrm{e}$ & $2,33 \mathrm{e}$ & $11,33 \mathrm{~d}$ & $14,67 \mathrm{c}$ \\
\hline $\mathrm{F}(\mathrm{T})$ & $40,68 * *$ & $64,67 * *$ & $61,43 * *$ & $344,97 * *$ \\
\hline $\mathrm{F}(\mathrm{G} \times \mathrm{T})$ & $0,87^{\mathrm{NS}}$ & $2,14 *$ & $0,75^{\mathrm{NS}}$ & $1,97 *$ \\
\hline C.V. $(\%)$ & 2,98 & 22,13 & 17,57 & 6,66 \\
\hline
\end{tabular}

(1) Médias seguidas de mesma letra na coluna não diferem estatisticamente entre si pelo teste de Tukey, a 5\% de probabilidade. Para análise, os dados foram transformados em arcoseno $(\mathrm{x} / 100)^{1 / 2}$. Na tabela, os dados são originais. ${ }^{(2)} \mathrm{DAP}=\mathrm{Dias}$ após a aplicação dos produtos. Ns Não significativo. **Significativo. *Significativo para $\mathrm{F}$ da interação.

Tabela 3: Desdobramento da interação genótipos de feijoeiro versus avaliação de terceiro dia após a aplicação dos produtos para a mortalidade média de ninfas (\%) de Bemisia tabaci biótipo B, em casa de vegetação. Jaboticabal, SP, 2012

\begin{tabular}{|c|c|c|c|c|}
\hline \multirow{2}{*}{ Tratamentos (T) } & \multicolumn{3}{|c|}{ Genótipos $(\mathbf{G})^{(1)}$} & \multirow{2}{*}{$\mathbf{F}(\mathbf{T})$} \\
\hline & Harmonia & Carioca & Pérola & \\
\hline Silício 1\% & $38,00 \mathrm{c} \mathrm{A}$ & $46,00 \mathrm{~b} \mathrm{~A}$ & $43,00 \mathrm{c} \mathrm{A}$ & $0,22^{\mathrm{NS}}$ \\
\hline $\operatorname{Nim} 1 \%$ & 97,50 a $\mathrm{A}$ & 92,50 a $\mathrm{AB}$ & $70,00 \mathrm{bc} \mathrm{B}$ & $5,22 * *$ \\
\hline Silício $1 \%+\operatorname{Nim} 0,25 \%$ & $73,00 \mathrm{bc} \mathrm{A}$ & $77,00 \mathrm{ab} \mathrm{A}$ & $86,00 \mathrm{ab} A$ & $1,89^{\mathrm{NS}}$ \\
\hline $\operatorname{Nim} 0,75 \%$ & $83,00 \mathrm{ab} B$ & 93,33 a $\mathrm{AB}$ & 100,00 a A & $5,07 * *$ \\
\hline $\operatorname{Nim} 0,50 \%$ & $79,00 \mathrm{ab} \mathrm{A}$ & $75,00 \mathrm{ab} A$ & $73,00 \mathrm{bc} \mathrm{A}$ & $0,35^{\mathrm{NS}}$ \\
\hline $\operatorname{Nim} 0,25 \%$ & $62,00 \mathrm{bc} \mathrm{A}$ & $62,00 \mathrm{~b} \mathrm{~A}$ & $66,00 \mathrm{bc} \mathrm{A}$ & $0,08^{\mathrm{NS}}$ \\
\hline Testemunha & $3,00 \mathrm{dA}$ & $1,00 \mathrm{c} \mathrm{A}$ & $3,00 \mathrm{~d} \mathrm{~A}$ & $0,25^{\mathrm{NS}}$ \\
\hline$F(G)$ & $21,29 * *$ & $23,24 * *$ & $24,41 * *$ & - \\
\hline
\end{tabular}

Rev. Ceres, Viçosa, v. 64, n.4, p. 376-383, jul/ago, 2017 
do produto. Vieira et al. (2012), avaliando produtos à base de óleo de nim, silício e a associação entre os dois produtos, não obtiveram diferença estatística para o número de ninfas, nas avaliações aos três e sete dias após a aplicação dos tratamentos. Neste trabalho, a associação entre o silício $1 \%$ e nim $0,25 \%$ obteve mortalidade de mais de $70,00 \%$ de ninfas, para todos os genótipos no terceiro dia de avaliação.

A interação entre os genótipos de feijoeiro e a avaliação total de ninfas após a aplicação dos produtos apresentou diferença significativa para a mortalidade de ninfas total (Tabela 4). Para o efeito de genótipos dentro de tratamentos, obteve-se mortalidade total de $100,00 \%$ para o óleo de nim, em todas as doses utilizadas e, também, para o tratamento silício $1 \%+\operatorname{nim} 0,25 \%$. Para o efeito de trata- mentos, dentro de genótipos, apenas houve diferença significativa para o óleo de nim, na dose $0,50 \%$, em que os genótipos IAC-Harmonia e Pérola obtiveram mortalidade total de $100,00 \%$ e o genótipo IAC-Carioca Tybatã, de $95,00 \%$. Em relação à aplicação de silício $1 \%$, observou-se que apesar de não ocasionar uma mortalidade de ninfas nos primeiros dias de avaliação, constatou-se mortalidade total acima de 90,00\%, para todos os genótipos, indicando ser um produto eficiente para o manejo da moscabranca.

Resultados semelhantes foram observados por Janini et al. (2011), que verificaram redução do número de ninfas de B. tabaci biótipo $\mathrm{B}$, aos 21 dias após emergência das plantas (DAE) de feijão comum, com aplicações de óleo de nim, sem diferença estatística nas doses de 0,50 e 1\%;

Tabela 4: Desdobramento da interação genótipos de feijoeiro versus avaliação total de ninfas após a aplicação dos produtos para a mortalidade total (\%) de ninfas de Bemisia tabaci biótipo B, em casa de vegetação. Jaboticabal, SP, 2012

\begin{tabular}{|c|c|c|c|c|}
\hline \multirow{2}{*}{ Tratamentos $(\mathrm{T})$} & \multicolumn{3}{|c|}{ 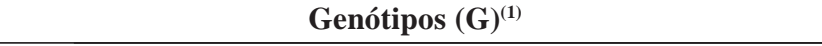 } & \multirow{2}{*}{$\mathbf{F}(\mathbf{T})$} \\
\hline & Harmonia & Carioca & Pérola & \\
\hline Silício $1 \%$ & $91,00 \mathrm{~b} \mathrm{~A}$ & 97,00 a $\mathrm{A}$ & 97,00 a A & $3,26^{\mathrm{NS}}$ \\
\hline $\operatorname{Nim} 1 \%$ & 100,00 a A & 100,00 a A & 100,00 a A & $0,00^{\mathrm{NS}}$ \\
\hline Silício $1 \%+\operatorname{Nim} 0,25 \%$ & 100,00 a A & 99,00 a $\mathrm{A}$ & 100,00 a $\mathrm{A}$ & $0,41^{\mathrm{NS}}$ \\
\hline $\operatorname{Nim} 0,75 \%$ & 100,00 a A & 100,00 a $\mathrm{A}$ & 100,00 a $\mathrm{A}$ & $0,00^{\mathrm{NS}}$ \\
\hline $\operatorname{Nim} 0,50 \%$ & 100,00 a A & 95,00 a B & 100,00 a $\mathrm{A}$ & $5,81 * *$ \\
\hline $\operatorname{Nim} 0,25 \%$ & 100,00 a A & 98,00 a A & 100,00 a A & $1,64^{\mathrm{NS}}$ \\
\hline Testemunha & $20,00 \mathrm{c} \mathrm{A}$ & $13,00 \mathrm{~b} \mathrm{~A}$ & $11,00 \mathrm{~b} \mathrm{~A}$ & $2,81^{\mathrm{NS}}$ \\
\hline$F(G)$ & $104,09 * *$ & $113,92 * *$ & $130,92 * *$ & \\
\hline
\end{tabular}

Tabela 5: Período médio de mortalidade de ninfas (PMMN), período ninfal (PN) e longevidade de adultos (LA), em dias, de Bemisia tabaci biótipo B, em genótipos de feijoeiro submetidos a aplicações de óleo de nim e de silício, em casa de vegetação. Jaboticabal, SP, 2012

\begin{tabular}{lccc}
\hline Genótipos (G) & $\mathbf{P M M N}^{(1)}$ & $\mathbf{P N}^{(2)}$ & $\mathbf{L A}^{(2)}$ \\
\hline IAC-Harmonia & $3,27 \mathrm{a}$ & 13,41 & 1,19 \\
IAC-Carioca Tybatã & $3,10 \mathrm{a}$ & 9,79 & 1,30 \\
Pérola & $3,32 \mathrm{a}$ & 10,59 & 1,20 \\
\hline F $(\mathrm{G})$ & $0,24^{\mathrm{NS}}$ & - & - \\
\hline Tratamentos (T) & & & 1,04 \\
\hline Silício 1\% & $5,29 \mathrm{a}$ & 9,66 & - \\
Nim 1\% & $1,81 \mathrm{~d}$ & $-(3)$ & 2,00 \\
Silício 1\% + Nim 0,25\% & $2,50 \mathrm{~cd}$ & 10,00 & - \\
Nim 0,75\% & $1,41 \mathrm{~d}$ & - & 1,00 \\
Nim 0,50\% & $2,63 \mathrm{~cd}$ & 8,33 & 1,00 \\
Nim 0,25\% & $3,72 \mathrm{bc}$ & 9,00 & 1,40 \\
Testemunha & $5,24 \mathrm{ab}$ & 13,56 & - \\
\hline F (T) & $19,08^{* *}$ & - & - \\
\hline F $(\mathrm{G} \mathrm{x} \mathrm{T)}$ & $0,43^{\mathrm{NS}}$ & - & - \\
\hline C.V. $(\%)$ & 43,01 & - & \\
\hline
\end{tabular}

${ }^{(1)}$ Médias seguidas da mesma letra na coluna não diferem estatisticamente entre si pelo teste de Tukey, a 5\% de probabilidade. Na tabela, os

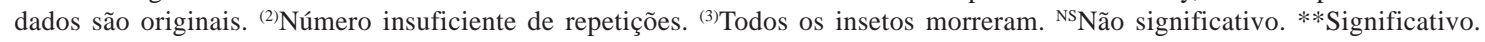


aos 35 DAE, obtiveram redução do número de ninfas com a dose de $1 \%$, em campo. Souza \& Vendramim (2005), verificando o efeito de extrato aquoso de sementes de nim na mortalidade de ninfas de $B$. tabaci biótipo B, relataram que a eficiência aumentou conforme aumento da concentração, com mortalidade de $38,2 \%$ para nim $0,5 \%$ e mortalidade de 68,4 e 99,6 respectivamente, para as doses de 1 e $5 \%$ em plantas de tomate.

O período médio de mortalidade de ninfas de $B$. tabaci biótipo B não apresentou diferença significativa entre os genótipos de feijão comum (Tabela 5). Entre os tratamentos, o menor período de mortalidade de ninfas foi para o óleo de nim, na dose de $0,75 \%$, não diferindo significativamente das doses de $1 \% ; 0,50 \%$ e silício $1 \%+$ nim $0,25 \%$. Coudriet et al. (1985), aplicando-se produtos à base de nim sobre ninfas de mosca-branca, observaram que a mortalidade máxima ocorreu entre dois e cinco dias após o tratamento. Esses resultados aproximam-se aos desta pesquisa, na qual o tempo médio de mortalidade de ninfas foi de 1,41 dias, verificando-se, com 6,00 dias, mortalidade de $98,00 \%$ das ninfas, com aplicação de óleo de nim na dose $0,75 \%$. Para o período ninfal e para a longevidade de adultos, não foram obtidos dados suficientes para a análise estatística, pois, nas doses de 0,75 e $1 \%$ de óleo de nim verificou-se que todas as ninfas morreram.

\section{CONCLUSÕES}

Não houve diferença significativa entre os genótipos de feijoeiro comum, para os testes de não preferência para oviposição de Bemisia tabaci biótipo B.

O óleo de nim, nas doses $1 \%, 0,75 \%$, e o silício $1 \%$ por via do solo e silício $0,125 \%$ por via foliar reduzem a oviposição de Bemisia tabaci biótipo B.

Não foi observada diferença significativa para a mortalidade de ninfas no $1^{\circ}, 3^{\circ}$ e $6^{\circ}$ dia após a aplicação do óleo de nim e para a mortalidade total de ninfas entre os genótipos avaliados.

Para a interação entre os genótipos de feijoeiro e aplicações dos produto, observou-se diferença significativa para o terceiro dia de avaliação, com mortalidade de mais de $50 \%$ das ninfas para todos os genótipos.

Todos os produtos utilizados são eficientes na mortalidade total de ninfas de $B$. tabaci, com destaque para as concentrações de 0,75 e $1 \%$ de óleo de nim, associados aos genótipos de feijoeiro comum avaliados. Para o silício $1 \%$, constatou-se mortalidade total acima de $90,00 \%$ para todos os genótipos.

\section{APOIO}

A primeira autora foi contemplada com bolsa de estudos de doutorado pela Capes.

\section{REFERÊNCIAS}

Almeida GD, Pratissoli D, Holtz AM \& Vicentini VB (2008) Fertilizante organomineral como indutor de resistência contra a colonização da mosca branca no feijoeiro. Idesia, 26:29-32.

Aragão FJL \& Faria JC (2005) Obtenção de feijoeiro resistente ao vírus do mosaico dourado. Goiânia, Embrapa. 111p.

Azevedo FR, Guimarães JA, Braga Sobrinho R \& Lima MAA (2005) Eficiência de produtos naturais para o controle de Bemisia tabaci biótipo B (Hemiptera: Aleyrodidae) em meloeiro. Arquivo do Instituto Biológico, 72:73-79.

Barbosa \& Maldonado Junior (2010) AgroEstat: Sistema para Análises Estatísticas de Ensaios Agronômicos. Versão 1.0. Jaboticabal, UNESP. CD-ROM.

Bleicher E, Gonçalves MEC \& Silva LD da (2007) Efeito de derivados de nim aplicados por pulverização sobre a mosca-branca em meloeiro. Horticultura Brasileira, 25:110-113.

Campos ZR, Boiça Junior AL, Lourenção AL \& Campos AR (2009) Parâmetros biológicos de Bemisia tabaci (Genn.) biótipo B (Hemiptera: Aleyrodidae) em genótipos de algodoeiro. Bragantia, 68:1003-1007.

Carneiro SM de TPG (2002) Ação do nim sobre fungos fitopatogênicos. In: Martinez SS (Ed.) O nim Azadirachta indi$c a$ - natureza, usos múltiplos, produção. Londrina, Instituto Agronômico do Paraná. p.59-64.

Correa RSB, Moraes JC, Auad AM \& Carvalho GA (2005) Silicon and acibenzolar-S-methyl as resistance inducers in cucumber, against the whitefly Bemisia tabaci (Gennadius) (Hemiptera: Aleyrodidae) biotype B. Neotropical Entomology, 34:429-433.

Coudriet DL, Prabhaker N \& Meyerdirk DE (1985) Sweetpotato whitefly (Homoptera: Aleyrodidae): Effects of neem-seed extract on oviposition and immature stages. Environmental Entomology, 14:776-779.

Datnoff LE, Raid RN, Snyder GH \& Jones DB (1991) Effect of calcium silicate on blast and brown spot intensities and yields of rice. Plant Disease, 75:729-732.

Epstein E (1994) The anomaly of silicon in plant biology. Proceedings National of Academy Science, 91:11-17.

Faria JC, Anjos JRN dos, Costa AF da, Sperândio CA \& Costa CL (1996) Doenças causadas por vírus e seu controle. In: Araújo RD, Rava CA, Stone LF \& Zimmermann MJ de O (Ed.) Cultura do feijoeiro comum no Brasil. Piracicaba, Potafos. p.731-769.

Ferrari Neto J (2016) Qualidade física e química do solo em função do sistema de produção e da aplicação superficial de silicato e calcário em experimento de longa duração. Tese de Doutorado. Universidade Estadual Paulista, Botucatu. 184p.

Godoy AF (2017) Comportamento alimentar de Bemisia tabaci biótipo B (Hemiptera: Aleyrodidae) em genótipos de soja na presença e ausência de silício. Dissertação de Mestrado. Universidade Estadual Paulista, Botucatu. 81p.

Gomes FB, Moraes JC \& Assis GA (2008) Silício e imidacloprid na colonização de plantas por Myzus persicae e no desenvolvimento vegetativo de batata inglesa. Ciência Rural, 38:1209-1213.

Gomes FB, Moraes JC \& Neri DKP (2009) Adubação com silício como fator de resistência a insetos-praga e promotor de produtividade em cultura de batata inglesa em sistema orgânico. Ciência e Agrotecnologia, 33:18-23.

Goussain MM, Morais JC, Carvalho JG, Nogueira NL \& Rossi ML (2002) Efeito da aplicação de silício em plantas de milho no desenvolvimento biológico da lagarta-do-cartucho Spodoptera frugiperda (J.E. Smith) (Lepidoptera: Noctuidae). Neotropical Entomology, 31:305-310. 
Janini JC, Boiça Junior AL, Jesus FG, Silva AG, Carbonell SA \& Chiorato AF (2011) Effect of bean genotypes, insecticides, and natural products on the control of Bemisia tabaci (Gennadius) biotype B (Hemiptera: Aleyrodidae) and Caliothrips phaseoli (Hood) (Thysanoptera: Thripidae). Acta Scientiarum Agronomy, 33:445-450.

Martinez SS (2002) Ação do nim sobre os insetos. In: Martinez SS (Ed.) O nim Azadirachta indica - natureza, usos múltiplos, produção. Londrina, IAPAR. p.31-57.

Peixoto ML \& Boiça Júnior AL (2014) Antibiose e não preferência para oviposição de Bemisia tabaci (Genn.) biótipo B (Hemiptera: Aleyrodidae) em genótipos de feijoeiro comum. Arquivos do Instituto Biológico, 81:134-139.

Peixoto ML, Moraes JC, Silva AA \& Assis FA (2011) Efeito do silício na preferência para oviposição de Bemisia tabaci biótipo B (GENN.) (HEMIPTERA: ALEYRODIDAE) em plantas de feijão (Phaseolus vulgaris L.). Ciência e Agrotecnologia, 35:478-481

Prabhaker N, Toscano NC \& Coudriet DL (1989) Susceptibility of the immature and adult stages of the sweetpotato whitefly (Homoptera: Aleyrodidae) to selected insecticides. Journal of Economic Entomology, 82:983-988

Quintela ED \& Pinheiro PV (2009) Redução da oviposição de Bemisia tabaci (Genn.) biótipo B (Hemiptera: Aleyrodidae) em folhas de feijoeiro tratadas com extratos botânicos. BioAssay, 4:01-10.
Rheinheimer AR, Alves LFA, Pietrowski V, Bellon PP, Miranda AM \& Gazola D (2012) Produtos fitossanitários alternativos no controle da mosca-branca (Bemisia tuberculata) (MatileFerrero), na mandioca. Semina: Ciências Agrárias, 33:14191426.

Silva AP, Bleicher E \& Araújo AC (2003) Eficiência de azadiractina no controle de mosca-branca em meloeiro sob condições de casa de vegetação e de campo. Horticultura Brasileira, 21:198201 .

Souza AP de \& Vendramim JD (2000) Efeito de extratos aquosos de meliáceas sobre Bemisia tabaci biótipo B em tomateiro. Bragantia, 59:173-179.

Souza AP de \& Vendramim JD (2005) Efeito translaminar, sistêmico e de contato de extrato aquoso de sementes de nim nobre Bemisia tabaci (Genn.) biótipo B em tomateiro. Neotropical Entomology, 34:83-87.

Vieira SS, Boff MIC, Bueno AF, Gobbi AL, Lobo RV \& Bueno RCO de F (2012) Avaliação da utilização de nim indiano em associação com silício e potássio no manejo da mosca branca na cultura da soja. BioAssay, 7:01-04. 